\title{
Gênero, ciências e tecnologias: caminhos percorridos e novos desafios*
}

\author{
Betina Stefanello Lima** \\ Maria Conceição da Costa***
}

\section{Resumo}

Este artigo analisa aspectos das políticas científicas para a equidade de gênero no sistema científico e tecnológico implementadas no âmbito do Programa Mulher e Ciência. Esse foi o primeiro programa, no âmbito do governo federal, com o objetivo de aumentar a participação das mulheres no sistema científico $e$ de fomentar a pesquisa no campo de gênero $e$ feminismos. Buscamos compreender o impacto dos resultados alcançados pelo programa para a consolidação da área de estudos de gênero, ciências e tecnologias e para a incorporação de gênero nas políticas de ciência e tecnologia do país.

Palavras-chave: Gênero, Ciências e Tecnologias, Política Científica e de Gênero, Programa Mulher e Ciência.

* Recebido em 18 de março de 2016, aceito em 08 de agosto de 2016.

** Analista em Ciência e Tecnologia do Conselho Nacional de Desenvolvimento Científico e Tecnológico (CNPq), Brasília, DF, Brasil. betinaskywalker@gmail.com

*** Professora no Instituto de Geociências, Unicamp, Campinas, SP, Brasil. dacosta@ige.unicamp.br 
Gender, Science and Technology: Traveled Paths and New Challenges

\begin{abstract}
The article analyzes scientific policies concerning gender equity in the science and technology system of the Program called "Women and Science". This was the first program within the federal government, whose objective was to increase female participation in the scientific system and promote research on gender and feminisms. Using the information gathered, we seek to understand the impact of the results achieved by the program for consolidating the gender studies, science and technology and the incorporation of gender in the country's science and technology policies.
\end{abstract}

Keywords: Gender, Science and Technology, Science and Technology Policies, Women and Science Program. 
O Programa Mulher e Ciência (PMC) é um marco nas questões de gênero, ciências e tecnologias. A institucionalização desse programa no âmbito do governo federal nos indica o reconhecimento por parte do Estado brasileiro, por meio dos seus inúmeros parceiros, da importância tanto de fortalecer os estudos sobre mulheres, relações de gênero e feminismos quanto de fomentar a participação feminina nas ciências. Esse reconhecimento aporta visibilidade ao tema da equidade de gênero na produção do conhecimento científico e tecnológico.

Implementado em 2005, o Programa Mulher e Ciência (PMC) é resultado da parceria entre Ministério de Ciência, Tecnologia e Inovação (MCTI), Conselho Nacional de Desenvolvimento Científico e Tecnológico ( $\mathrm{CNPq})$, Secretaria de Políticas para as Mulheres (SPM), Ministério da Educação (MEC), Ministério de Desenvolvimento Agrário (MDA) e ONU-Mulheres. O programa possui dois objetivos principais: estimular a produção científica e a reflexão acerca das relações de gênero, mulheres e feminismos no país; promover a participação das mulheres no campo das ciências e carreiras acadêmicas. A fim de atingir seus objetivos, o programa realiza três ações centrais: 1) Prêmio anual Construindo a Igualdade de Gênero; 2) Chamada bienal de apoio a projetos de pesquisa na área de mulheres, relações de gênero e feminismos; 3 ) Encontro Nacional de Núcleos e Grupos de Pesquisa Pensando Gênero e Ciências.

Os estudos de gênero, ciências e tecnologias (EGCT) desempenham um papel fundamental para subsidiar a formulação de políticas para promoção da equidade de gênero nas ciências e tecnologias. Tendo em vista a importância desse campo de estudos, nosso objetivo neste artigo é analisar como os Estudos de gênero, ciências e tecnologias têm se configurado no Brasil por meio da literatura existente e dos dados das quatro chamadas públicas $^{1}$ de apoio à pesquisa na área de mulheres, relações de

1 A partir de 2011, o Conselho Nacional de Desenvolvimento Científico e Tecnológico (CNPq) passou a utilizar o termo "chamada pública" em vez de "edital". 
gênero e feminismos no âmbito do Programa Mulher e Ciência. Também buscamos entender se essas ações fortaleceram ou não essa área de pesquisa. ${ }^{2}$

A chamada pública para apoio a projetos de pesquisa é um dos instrumentos do CNPq para concessão de recursos para a pesquisa. Nas chamadas do programa analisado poderiam concorrer pesquisadoras/es doutoras/es com pesquisas e estudos "relacionados aos temas relações de gênero, mulheres $e$ feminismos, buscando contemplar a intersecção com as seguintes abordagens: classe social, geração, raça, etnia e sexualidade" ${ }^{3}$ Os valores são destinados ao gasto com custeio (ex. despesas com passagens) e com capital (ex. compra de equipamento). Na última chamada houve também concessão de bolsas para integrantes da equipe.

Pode-se considerar que o fomento para a área de gênero, ciências e tecnologias está contemplado nos objetivos do programa, uma vez que neles está previsto estimular a produção científica no campo de gênero e feminista, que engloba os estudos de gênero, ciências e tecnologias. Também consideramos que o PMC ao almejar promover a participação feminina nas ciências $e$ tecnologias também contribui com a reflexão sobre carreiras científicas e gênero.

Consideramos estudos de gênero, ciências e tecnologias (EGCT) o conjunto de pesquisas que conjugam esses termos em suas distintas e, por vezes, conflitantes abordagens. São pesquisas que buscam analisar as relações que permeiam e estruturam os fazeres e saberes científicos e tecnológicos. Esses estudos compartilham um objetivo político: "a oposição ao sexismo e ao androcentrismo que se observam na prática científica" (Garcia,

2 Este artigo é resultado da pesquisa que está sendo desenvolvida no doutorado por Betina Stefanello Lima sob orientação Maria Conceição da Costa e Maria Margaret Lopes.

3 Trecho extraído da Chamada 32/2012. 
Marta I. G.; Sedeño, Eulália P., 2006). ${ }^{4}$ A construção desse campo de pesquisa se inicia com questionamentos sobre a sub-representação das mulheres nas ciências ${ }^{5}$ e que se expandiram para questionamentos sobre a própria estrutura científica ${ }^{6}$ e para o impacto da ausência de mulheres e da incorporação da perspectiva de gênero nas ciências. ${ }^{7}$

Para análise do campo de estudos de gênero, ciências e tecnologias no Brasil, analisaremos as propostas com essa temática submetidas nas quatro chamadas realizadas no âmbito do Programa Mulher e Ciência. Consideramos que a análise dessas propostas nos permitirá compor um panorama desse campo de estudos bem como verificar se o programa fomentou essa área de pesquisa.

No total de 1371 propostas enviadas nas quatro chamadas, foram enquadradas 74 como pertencentes à área de gênero, ciências e tecnologias, ou seja, cerca de $5,4 \%$ da demanda. A classificação temática foi proposta segundo a análise do título do projeto, do resumo, das palavras-chaves, da área do projeto escolhida pela/o proponente e da área de atuação. Em muitos casos, também analisamos as informações curriculares (Currículo Lattes) das/os proponentes. Evidentemente alguns projetos poderiam ser enquadrados em mais de uma categoria. Abaixo apresentamos o esquema de classificação temática:

4 Neste artigo, compartilhamos a posição de autoras como Consuelo Miqueo et al (2011) que argumentam a favor da visibilização das autoras por meio da citação de nome e sobrenome.

5 Margaret Rossiter (1982), ao analisar a situação das pesquisadoras norteamericanas, pode ser considerada uma das pioneiras nessa vertente de estudos. No Brasil, a publicação do Laboratório de Pandora, pela Profa. Fanny Tabak, é um marco nessa área.

${ }^{6}$ Estudos centrados em denunciar o androcentrismo da própria prática científica (Keller, Evelyn F., 1989) e propor uma epistemologia feminista (Harding, Sandra, 2006).

7 Estudos que buscam indicar as consequências do sexismo no conhecimento científico (Martin, Emily, 2006; Rohden, Fabíola, 2001) e apontar a transformação da produção científica a partir da inserção da perspectiva de gênero (Schiebinger, Londa, 2008; Keller, Evelyn F., 2006). 
Tabela 1 - Classificação temática das propostas das chamadas do Programa Mulher e Ciência

\begin{tabular}{|c|c|c|}
\hline Temas & Sub-temas & Intersecções \\
\hline Trabalho e economia & & \multirow{19}{*}{$\begin{array}{l}\text { geração, raça e } \\
\text { etnicidade, } \\
\text { geração, classe }\end{array}$} \\
\hline \multirow{3}{*}{ Arte, literatura e cultura } & Arte & \\
\hline & Literatura & \\
\hline & Cultura & \\
\hline \multicolumn{3}{|l|}{ Sexualidade e afetividade } \\
\hline \multirow{3}{*}{ Rural, floresta e meio-ambiente } & Rural & \\
\hline & Floresta & \\
\hline & Meio-ambiente & \\
\hline $\begin{array}{c}\text { Participação política e } \\
\text { movimentos sociais }\end{array}$ & & \\
\hline \multicolumn{2}{|l|}{ Saúde e direitos reprodutivos } & \\
\hline \multicolumn{2}{|l|}{ Políticas públicas } & \\
\hline \multicolumn{2}{|l|}{ Educação } & \\
\hline \multicolumn{2}{|l|}{ Esporte e Educação física } & \\
\hline \multicolumn{2}{|l|}{ Mídia e comunicação } & \\
\hline \multicolumn{2}{|l|}{$\begin{array}{c}\text { História das mulheres, do } \\
\text { feminismo e das relações de } \\
\text { gênero }\end{array}$} & \\
\hline \multicolumn{2}{|l|}{ Violência } & \\
\hline \multicolumn{2}{|l|}{ Teoria feminista e de gênero } & \\
\hline \multirow{3}{*}{ Gênero, ciências e tecnologias } & $\begin{array}{c}\text { Trajetórias/história de } \\
\text { mulheres em Ciência e } \\
\text { Tecnologia }\end{array}$ & \\
\hline & $\begin{array}{l}\text { Carreiras de mulheres } \\
\text { em CT e Política } \\
\text { Científica e Tecnológica }\end{array}$ & \\
\hline & $\begin{array}{c}\text { Epistemologia/Teorias } \\
\text { de gênero e C\&T }\end{array}$ & \\
\hline
\end{tabular}




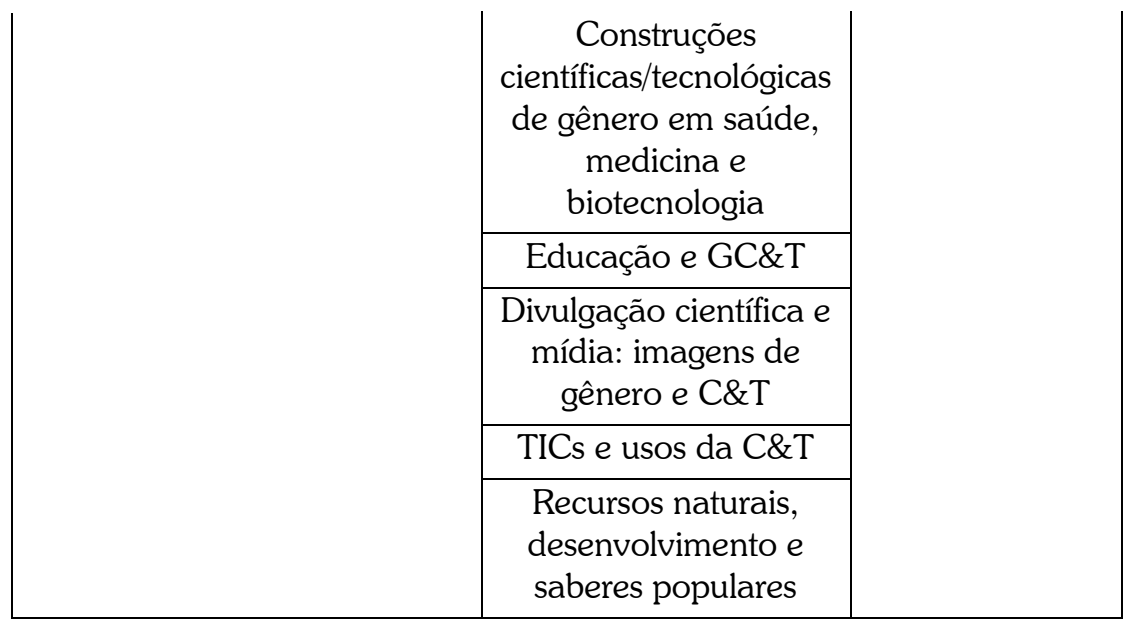

Esse percentual pode ser considerado baixo no âmbito do programa que justamente visibiliza as questões de gênero $e$ ciências. Conforme o quadro abaixo, constata-se que a primeira chamada (45/2005) recebeu o maior número de propostas. Houve um decréscimo nas chamadas em 2008 (57/2008) e 2010 (20/2010) e, em 2012 (32/2012), houve um aumento sem, todavia, alcançar o total enviado em 2005.

Tabela 2 - Dados da demanda nos estudos de gênero, ciências e tecnologias por chamada

\begin{tabular}{|c|c|c|c|c|c|}
\hline Demanda & \multicolumn{5}{|c|}{ Número de projetos enviados } \\
\hline Subtema & $45 / 2005$ & $57 / 2008$ & $20 / 2010$ & $32 / 2012$ & total \\
\hline $\begin{array}{c}\text { Gênero, ciências } \\
\text { e tecnologias }\end{array}$ & 26 & 12 & 15 & 21 & 74 \\
\hline
\end{tabular}

O fato de a primeira chamada (45/2005) ter sido a que apresentou a maior demanda sobre o tema (26 propostas) indica que esse campo de estudos, mesmo sendo de interesse central para o Programa Mulher e Ciência, não foi, ainda, incentivado de forma a representar uma significativa expansão dessa área. 
É importante lembrar que a linha de pesquisa de gênero $e$ ciências foi destacada na quarta chamada (32/2012) como um tema prioritário. A definição dos temas prioritários está imersa na disputa entre as prioridades institucionais de cada parceiro do Programa Mulher e Ciência. A linha de gênero e ciências foi sugerida pela equipe do $\mathrm{CNPq}$.

As linhas temáticas elencadas como preferenciais da última chamada (32/2012) não tiveram uma reserva de recursos financeiros, com exceção da linha associada às temáticas rurais $e$ da floresta que, desde 2008, com a participação do Ministério de Desenvolvimento Agrário (MDA), conta com um aporte de recursos específico. A medida de elencar linhas temáticas prioritárias, sem reserva de recursos, não se demonstrou suficiente para o fomento temático, como no caso da área de gênero $e$ ciências, em que não houve aumento no número de propostas como é possível verificar na Tabela 2.

Um panorama sobre o perfil das/os proponentes de projetos em Gênero, Ciências e Tecnologias nas chamadas

Analisamos as 74 propostas (de um total de 1371) que enquadramos na área de gênero, ciências e tecnologias, nas quatro chamadas do PMC, segundo o perfil das/os proponentes. Os projetos submetidos nas quatro chamadas foram enviados por 61 pesquisadoras/es: $80 \%$ das pesquisadoras/es enviaram uma única proposta (49 proponentes), 18\% enviaram duas propostas, ou seja, participaram de 2 chamadas distintas (11 proponentes), $e$ $2 \%$ enviaram 3 propostas, ou seja, participaram de 3 chamadas (somente 1 proponente). A fim de traçar o perfil geral das/os proponentes, contabilizamos as repetições por entender que devemos visibilizar as participações "múltiplas".

As características da demanda de gênero, ciências $e$ tecnologias são semelhantes às da demanda geral do campo de gênero em termos de perfil (sexo, raça/cor, área do conhecimento de origem) das/os proponentes analisadas/os neste artigo e de trabalhos anteriores sobre autores/as em publicações de gênero $e$ 
feminista (Diniz, Débora; Foltran, Paula, 2004; Scavone, Lucila, 2013; Piscitelli, Adriana et al, 2003).

A maioria das/os coordenadores/as que enviaram propostas (total: 74) nas quatro chamadas do Programa Mulher e Ciência, na área de Estudos de Gênero, Ciências e Tecnologias, é do sexo feminino, cerca de $82 \%$ (total: 61). O percentual de aprovação de projetos coordenados por mulheres foi ainda maior: 94\% (33 projetos aprovados do total de 35). Esse percentual é um pouco maior que a média de aprovação geral (85\% do total de 1371), ou seja, do conjunto de projetos de todas as temáticas elencadas na Tabela 1.

Tabela 3: Dados das/dos proponentes por sexo e parecer

\begin{tabular}{|l|c|c|c|c|}
\hline \multicolumn{1}{|c|}{ Sexo } & Desfavorável & Favorável & Total & $\begin{array}{c}\text { \% de } \\
\text { aprovação }\end{array}$ \\
\hline Feminino & 28 & 33 & 61 & 54 \\
\hline Masculino & 11 & 2 & 13 & 15 \\
\hline Total & 39 & 35 & 74 & 47 \\
\hline
\end{tabular}

Destacamos que somente dois projetos encaminhados por coordenadores homens (do total de 11), cerca de 15\%, foram aprovados. Assim, além de poucos pesquisadores homens terem submetido proposta no tema, menor ainda foi o número de projetos aprovados. Um dos projetos aprovados se propõe a estudar a relação entre cibercultura e gênero, o outro projeto estuda os papéis desempenhados pelas mulheres no Programa de Pesquisas Antártico Brasileiro.

Em relação ao perfil étnico-racial, segundo a autodeclaração no Currículo Lattes, a maioria dos projetos enviados $(65 \%)$ e aprovados $(71 \%)$ são coordenados por pesquisadores/as brancas/os. A menor participação foi de pesquisadores/as pretas/os. Somente uma coordenadora se autodeclarou preta; seu projeto foi aprovado e versa sobre a participação negra nas ciências. 
Não houve participação de pesquisadores indígenas. Houve uma pesquisadora autodeclarada amarela que concorreu em duas chamadas e não teve aprovados seus projetos, ambos com mesmo conteúdo. Na última chamada, seu projeto não foi aprovado por ter sido submetido na categoria 2 e a pesquisadora pertencia a categoria 1 - com mais de 5 anos de titulação no doutorado.

Conforme os dados encontrados, o perfil étnico-racial encontrado no campo de estudos de gênero, ciências e tecnologias é predominantemente branco. Esses dados são similares ao perfil geral dos/as pesquisadores/as do campo feminista e de gênero, como também de todas as outras áreas do conhecimento. O perfil geral do quadro de pesquisadores do $\mathrm{CNPq}$, segundo autodeclaração de raça/cor dos/as bolsistas de Produtividade em Pesquisa, é de maioria branca: $75,5 \%$ de mulheres brancas $e$ $67,1 \%$ de homens brancos (Tavares, Isabel et al., 2015). A maioria das/os aprovadas/os nas quatro chamadas de Relações de Gênero, Mulheres e Feminismos, 65,4\%, se autodeclara branca, e 82\% dos quatro comitês de julgamento das chamadas do Programa Mulher e Ciência também é de brancos/as. Temos o desafio de pluralizar a participação étnico-racial na ciência e tecnologia.

Tabela 4 - Dados das/dos coordenadores dos EGCT por raça e cor segundo CV Lattes

\begin{tabular}{|l|c|c|c|c|}
\hline \multicolumn{1}{|c|}{ Raça/cor } & Desfavorável & Favorável & Total & $\begin{array}{c}\text { \% de } \\
\text { aprovação }\end{array}$ \\
\hline Amarela & 2 & & 2 & 0 \\
\hline Branca & 23 & 25 & 48 & 52 \\
\hline Não atualizado & 2 & 3 & 5 & 60 \\
\hline Não informada & 6 & 4 & 10 & 40 \\
\hline Parda & 6 & 2 & 8 & 25 \\
\hline Preta & & 1 & 1 & 100 \\
\hline Totais & 39 & 35 & 74 & 47 \\
\hline
\end{tabular}


Outro destaque é que 7\% (5 coordenadores/as do total de 74) das/os pesquisadores não tinham atualizado seus currículos depois de 2013, o que indica, provavelmente, que não são pesquisadores beneficiários de bolsas ou auxílios, uma vez que a análise do Currículo Lattes é requisito para qualquer solicitação enviada ao CNPq. Esse dado pode apontar que uma parte das/os que submeteram proposta no período pesquisado não é de pesquisadores ativos atualmente ou tiveram uma pequena inserção no sistema de C\&T. Cerca de 13\% (10 coordenadores/as do total de 74) escolheram não informar sua raça/cor. Assim, percebe-se que ainda que gênero tenha sido um marcador aceito como importante para a pesquisa, raça/etnia não o foi. Esse percentual - de quem não quis identificar seu pertencimento étnico-racial - é similar ao conjunto de aprovadas/os nas quatro chamadas em todas as temáticas (9,3\% do total de 1371). Portanto, é necessário atentar para as distintas questões para a plena participação feminina nas ciências. Consideramos que a participação das mulheres negras e indígenas na $C \& T$ ainda é um assunto a ser melhor inserido na pauta dos Estudos de Gênero, Ciências e Tecnologias e também no Programa Mulher e Ciência que, até o presente momento, não tem uma ação específica direcionada para o recorte étnico-racial na pesquisa, apesar da significativa participação negra no Prêmio Construindo a Igualdade de Gênero ${ }^{8}$ e dos textos das chamadas Relações de Gênero, Mulheres e Feminismos atentarem para as intersecções. ${ }^{9}$

Verificamos também se as/os pesquisadores/as dos projetos de Estudos de Gênero Ciências e Tecnologias identificavam nas

\footnotetext{
8 Esse prêmio é um concurso de redações, de artigos científicos e propostas pedagógicas que tratam das questões de gênero, mulheres e feminismos.

9 Trecho da Chamada 20/2010: "tem por objetivo selecionar propostas para apoio financeiro a projetos que visem a contribuir significativamente para o desenvolvimento científico e tecnológico do País, estimulando e fortalecendo a produção de pesquisas e estudos relacionados aos temas relações de gênero, mulheres $e$ feminismos, buscando contemplar a intersecção com as seguintes abordagens: classe social, geração, raça, etnia e sexualidade".
} 
linhas de pesquisa, do Currículo Lattes vertentes pertencentes, em suas diversas abordagens, a essa área.

Tabela 5 - Linhas de Pesquisa do Currículo Lattes elencadas por proponentes

\begin{tabular}{|l|c|c|}
\hline $\begin{array}{c}\text { Enquadramento se possui linha temática relacionada } \\
\text { ao EGCT }\end{array}$ & Favorável & Demanda \\
\hline Não possui linha relacionada EGCT & 24 & 55 \\
\hline Possui linha relacionada aos EGCT & 7 & 13 \\
\hline Não elencou linhas de pesquisa & 4 & 6 \\
\hline Totais & 35 & 74 \\
\hline
\end{tabular}

Percebemos, segundo os dados apresentados na Tabela 5, que somente $18 \%$ dos projetos enviados (13) são de pesquisadores que elencaram nas linhas de pesquisa do Currículo Lattes temas de pesquisa relacionados aos Estudos de Gênero, Ciências e Tecnologias. O restante ( $74 \%$ - 55 proponentes do total de 74 ) não identificou em suas linhas de pesquisa vertentes relacionadas aos EGCT. Em alguns casos, as/os pesquisadores listaram linhas de pesquisa relacionadas aos Estudos Sociais da Ciência $e$ Tecnologia (inovação tecnológica) ou aos Estudos Feministas e de Gênero (mercado de trabalho por gênero). Um pequeno número de currículos (6 pesquisadores ou $8 \%$ ) não possuía linhas de pesquisa preenchidas.

A maioria dos/das proponentes que enviou propostas nas chamadas não possuir linha de pesquisa relacionada aos Estudos de Gênero, Ciências e Tecnologias pode indicar que há poucas/os pesquisadores/as no Brasil que se dedicam efetivamente a essa temática. Sem, contudo, deixar de considerar que pode haver um número pequeno de pesquisadoras atuantes na área que não identificaram em suas linhas de pesquisa temáticas da área EGCT. 
cadernos pagu(48), 2016:e164805 Betina S. Lima e Maria Conceição da Costa

Tabela 6: Linhas de Pesquisa de EGCT listadas por proponentes e por parecer

\begin{tabular}{|l|c|c|c|}
\hline $\begin{array}{c}\text { Linha de Pesquisa relacionada aos } \\
\text { EGCT }\end{array}$ & Desfavorável & Favorável & Total \\
\hline Ciência, educação e gênero & 1 & & 1 \\
\hline Gênero e Ciência & 2 & 2 & 4 \\
\hline Gênero e História da Ciência & 1 & 1 & 2 \\
\hline Gênero, Ciência e Tecnologia & 1 & 1 & 2 \\
\hline $\begin{array}{l}\text { Gênero, práticas e discursos } \\
\text { científicos }\end{array}$ & & 1 & 1 \\
\hline $\begin{array}{l}\text { História das Ciências e da } \\
\text { Tecnologia e Gênero }\end{array}$ & 1 & 1 & 1 \\
\hline Mulher na Área Tecnológica & & 1 & 1 \\
\hline $\begin{array}{l}\text { Relações de gênero e } \\
\text { produção científica }\end{array}$ & 6 & 7 & 13 \\
\hline Totais & & & 1 \\
\hline
\end{tabular}

Conforme apresentado na Tabela 6, "gênero e ciência" é a linha que mais aparece nos currículos das/os proponentes. Sem dúvida, pela difusão desses termos, em literatura internacional, a partir da publicação de Evelyn Fox Keller, em 1978, como expressão para mapear a emergência de uma "nova" área de estudos.

A maioria dos projetos enviada e classificada no eixo temático gênero, ciências e tecnologias foi enquadrada na área de Ciências Humanas (67\%). O segundo maior percentual foi em Ciências Sociais Aplicadas (16\%). Os percentuais de propostas aprovadas foram similares aos da demanda - as Ciências Humanas (65\%) e Sociais Aplicadas (17\%) também foram as com maior percentual de propostas aprovadas. A concentração dos Estudos de Gênero, Ciências e Tecnologias nas Ciências Humanas é uma característica que tem sido confirmada em outros estudos (Cabral, Carla, 2015). Lembramos que essa também é uma 
característica apontada para os Estudos Feministas e de Gênero (Scavone, Lucila, 2013).

\section{Gráfico 1}

Percentual de propostas enviadas por grande área nos GCT nas quatro chamadas do PMC

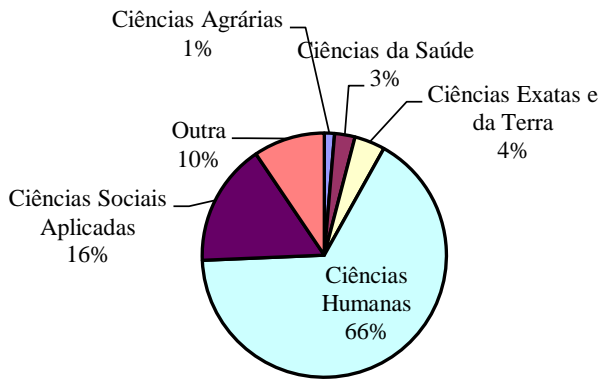

口Ciências Agrárias

口Ciências da Saúde

口Ciências Exatas e da Terra

口Ciências Humanas

-Ciências Sociais Aplicadas

口Outra

Gráfico 2

Percentual de propostas aprovadas por grande área nos GCT nas quatro chamadas do PMC

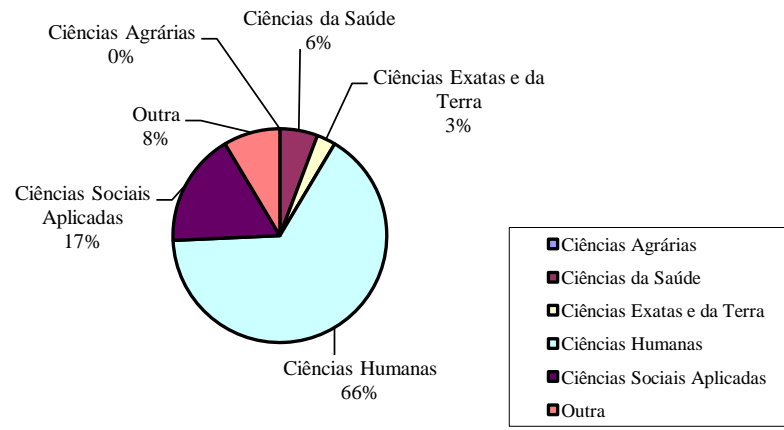


Esses dados indicam ainda que a maior parte dos estudos na área de EGCT está concentrada nas áreas de Humanas e Sociais Aplicadas. Diferentemente do que ocorre, por exemplo, no contexto norte-americano, são poucas iniciativas de incorporação da discussão de gênero por pesquisadoras/es de outras áreas (exatas, biológicas, da saúde). Conforme já apontava Margaret Lopes:

Diferentemente da tradição norte-americana, e das primeiras décadas do século no Rio de Janeiro, em que mulheres naturalistas e engenheiras tiveram um papel profissional e político atuante, os movimentos feministas desde o final da década de 1970, no Brasil, não incorporaram ou geraram qualquer tipo de contingente expressivo de mulheres que se dedicassem ou viessem a se dedicar às ciências naturais e exatas. É certo que o número de mulheres nessas carreiras aumentou, mas isso não significou qualquer mudança nas ciências, nem tampouco a criação de tradições de análise "engendradas" sobre as ciências (Lopes, Maria M., 1998:364).

No Brasil, essa concentração dificulta que essa discussão seja realizada de modo transversal e tenha maior impacto na estrutura científica e tecnológica. Os obstáculos para a incorporação da discussão feminista e de gênero nas áreas não relacionadas às Humanas e Sociais são consideráveis. Esta dificuldade pode ser derivada de múltiplas razões, uma delas, o não reconhecimento da questão de gênero como fator estruturante da ciência e tecnologia é pautado no discurso mertoniano que caracteriza o sistema científico como meritocrático e neutro (Lima, Betina S., 2013). O envolvimento com as questões de gênero e feministas ainda pode gerar preconceito entre os pares, uma vez que isso representa um questionamento sobre o discurso hegemônico da ciência e tecnologia. Assim, pode dificultar parcerias e alianças.

A incorporação da discussão feminista e de gênero tem sido apontada na literatura como uma das ações que efetivamente 
poderiam atrair mais mulheres para a C\&T (Schiebinger, Londa, 2008). Assim, essa temática não deveria estar tão concentrada nas Humanas e Sociais, pois isso dificulta a necessária transformação na estrutura científica e tecnológica. Sem uma mudança estrutural, a promoção de ações de inclusão são construídas em uma arquitetura concebida para excluir o feminino, uma vez que a ciência, institucionalizada e alocada no espaço público, foi constituída em valores centrados no masculino (Schiebinger, Londa, 2008). Isso não significa dizer que ações para inclusão não representam avanços, mas são avanços lentos e, frequentemente, tangenciais.

No Brasil, como já afirmamos, a temática gênero, ciências e tecnologias é caracterizada por uma dupla marginalidade. Não é um tema de visibilidade no campo de Estudos feministas e de Gênero e tampouco o é nos Estudos Sociais da Ciência e Tecnologia. Além da marginalidade do tema nesses campos, nos quais a temática pode ser considerada de interesse fundamental, as abordagens em cada uma dessas áreas parte de uma concepção distinta de ciência, em que a objetividade surge, grosso modo, como um divisor de águas. Nos Estudos Feministas e de Gênero encontramos muitas ressignificações do conceito de objetividade; já nos Estudos Sociais da Ciência e Tecnologia, a objetividade deixa de ser um valor atemporal e central do conhecimento científico (Lopes, Maria M., 1998, 2006).

$\mathrm{Na}$ Tabela 7, apresentamos a distribuição das propostas submetidas, segundo aprovação, por área de conhecimento:

Tabela 7 - Número de propostas por áreas do conhecimento listadas por proponentes

\begin{tabular}{|l|r|r|r|r|}
\hline \multicolumn{1}{|c|}{ Área do conhecimento } & DF & FV & Total & \% de aprovação \\
\hline Sociologia & 8 & 9 & 17 & 53 \\
\hline Educação & 7 & 8 & 15 & 53 \\
\hline História & 8 & 1 & 9 & 11 \\
\hline
\end{tabular}


cadernos pagu(48), 2016:e164805 Betina S. Lima e Maria Conceição da Costa

\begin{tabular}{|l|r|r|r|r|} 
Administração & 5 & 1 & 6 & 17 \\
\hline Antropologia & 2 & 3 & 5 & 60 \\
\hline Divulgação Científica & 2 & 2 & 4 & 50 \\
\hline Outra & 2 & 1 & 3 & 33 \\
\hline Ciência da Informação & & 2 & 2 & 100 \\
\hline Economia Doméstica & & 2 & 2 & 100 \\
\hline Física & 1 & 1 & 2 & 50 \\
\hline Saúde Coletiva & & 2 & 2 & 100 \\
\hline Arqueologia & & 1 & 1 & 100 \\
\hline Arquitetura e Urbanismo & 1 & & 1 & 0 \\
\hline Ciência da Computação & 1 & & 1 & 0 \\
\hline Comunicação & & 1 & 1 & 0 \\
\hline Geografia & 1 & & 1 & 100 \\
\hline Psicologia & & 1 & 1 & 0 \\
\hline $\begin{array}{l}\text { Recursos Florestais } e \\
\text { Engenharia Florestal }\end{array}$ & 1 & & 1 & 47 \\
\hline Totais & 39 & 35 & 74 & \\
\hline
\end{tabular}

Mais da metade das propostas enviadas foram dirigidas às áreas de Sociologia, Educação e História (41 propostas/total: 74). A Sociologia e a Educação também tiveram destaque na classificação de aprovação. Lembramos que a escolha das áreas para enquadramento dos projetos é feita pelas/os proponentes e frequentemente reflete a área de formação e atuação da/o coordenadora do projeto. No entanto, no caso da Física, na Tabela 7, a proponente é da área, mas propôs um projeto sobre mulheres na Física.

A distribuição da demanda da área de Estudos de gênero, ciências e tecnologias foi pulverizada em 42 instituições, a maioria tendo enviado somente uma proposta, conforme apresentamos na tabela abaixo classificada por maior número de propostas aprovadas: 
Tabela 8 - Número de propostas por instituição do/a proponente e por parecer

\begin{tabular}{|l|c|c|c|}
\hline \multicolumn{1}{|c|}{ Instituição } & Desfavorável & Favorável & Totais \\
\hline Universidade Estadual de Campinas & 5 & 3 & 8 \\
\hline Fundação Oswaldo Cruz & 2 & 2 & 4 \\
\hline Universidade Federal da Bahia & 2 & 2 & 4 \\
\hline Universidade Federal de Minas Gerais & 1 & 3 & 4 \\
\hline Universidade Federal de Viçosa & & 4 & 4 \\
\hline Universidade do Estado do Rio de Janeiro & & 3 & 3 \\
\hline Universidade Estadual de Londrina & 1 & 2 & 3 \\
\hline $\begin{array}{l}\text { Universidade Federal do Rio Grande do } \\
\text { Norte }\end{array}$ & 1 & 2 & 3 \\
\hline $\begin{array}{l}\text { Empresa Brasileira de Pesquisa } \\
\text { Agropecuária }\end{array}$ & 1 & 1 & 2 \\
\hline Universidade Estadual de Maringá & 2 & & 2 \\
\hline Universidade Federal de Campina Grande & 2 & & 2 \\
\hline Universidade Federal de Pernambuco & 1 & 1 & 2 \\
\hline Universidade Federal de Santa Catarina & 1 & 1 & 2 \\
\hline Universidade Federal do Rio de Janeiro & 1 & 1 & 2 \\
\hline Universidade Federal do Rio Grande do Sul & 1 & 1 & 2 \\
\hline Academia Brasileira de Ciências & & 1 & 1 \\
\hline Centro Brasileiro de Pesquisas Físicas & & 1 & 1 \\
\hline Centro Universitário Ritter dos Reis & 1 & & 1 \\
\hline Fundação Carlos Chagas & & & 1 \\
\hline $\begin{array}{l}\text { Fundação Centro de Ciências e Educação } \\
\text { Superior à Distância do Estado do RJ }\end{array}$ & & & 1 \\
\hline Instituto de Ensino Superior COC & & & 1 \\
\hline $\begin{array}{l}\text { Instituto de Pesquisas Tecnológicas do } \\
\text { Estado de São Paulo }\end{array}$ & & & \\
\hline $\begin{array}{l}\text { Instituto Federal de Educação, Ciência e } \\
\text { Tecnologia de Mato Grosso do Sul }\end{array}$ & & & 1 \\
\hline
\end{tabular}




\begin{tabular}{|l|c|c|c|} 
Museu de Astronomia e Ciências Afins & 1 & & 1 \\
\hline $\begin{array}{l}\text { Pontifícia Universidade Católica de São } \\
\text { Paulo }\end{array}$ & 1 & & 1 \\
\hline $\begin{array}{l}\text { Pontifícia Universidade Católica do Rio } \\
\text { Grande do Sul }\end{array}$ & 1 & 1 & 1 \\
\hline Sociedade Brasileira de Física & & & 1 \\
\hline Universidade de Brasília & 1 & 1 & 1 \\
\hline Universidade de São Paulo & 1 & 1 & 1 \\
\hline $\begin{array}{l}\text { Universidade do Estado do Rio Grande do } \\
\text { Norte }\end{array}$ & & & 1 \\
\hline Universidade do Sul de Santa Catarina & 1 & 1 & 1 \\
\hline $\begin{array}{l}\text { Universidade Estadual do Norte Fluminense } \\
\text { Darcy Ribeiro }\end{array}$ & 1 & 1 & 1 \\
\hline Universidade Federal de Alagoas & 1 & & 1 \\
\hline Universidade Federal de São Carlos & 1 & & 1 \\
\hline Universidade Federal do Ceará & 1 & & 1 \\
\hline Universidade Federal do Espírito Santo & 1 & & 1 \\
\hline Universidade Federal do Pará & 1 & & 1 \\
\hline Universidade Federal do Paraná & & & 1 \\
\hline Universidade Federal Fluminense & & & 1 \\
\hline $\begin{array}{l}\text { Universidade Federal Rural do Rio de } \\
\text { Janeiro }\end{array}$ & 1 & & 1 \\
\hline Universidade Presbiteriana Mackenzie & & & 1 \\
\hline $\begin{array}{l}\text { Universidade Tecnológica Federal do } \\
\text { Paraná }\end{array}$ & 1 & & 1 \\
\hline Totais & & & 1 \\
\hline
\end{tabular}

A Universidade Estadual de Campinas (Unicamp) enviou o maior número de propostas (8) e a segunda (empatada com a UFMG e UERJ) no número de aprovação. O Núcleo de Estudos de Gênero - Pagu, por meio de sua publicação cadernos pagu em 1998 (número 10), foi precursor no lançamento de um dossiê 
contemplando a intersecção entre os temas gênero, ciências $e$ tecnologia. A maior parte das publicações do cadernos pagu com esta temática estão distribuídos nos três dossiês: "Gênero, tecnologia, ciência" (1998); "Gênero, ciências, história" (2000); "Ciência, substantivo feminino, plural" (2006).

A Universidade Tecnológica Federal do Paraná (UTFPR) é outra instituição com forte atuação no tema, apesar da pouca visibilidade nas chamadas. Por ela são publicados, a partir de 2005, os Cadernos de Gênero e Tecnologia, do Grupo de Estudos e Pesquisas sobre Relações de Gênero e Tecnologia (GeTec), e a Revista Tecnologia e Sociedade, do Programa de Pós-Graduação em Tecnologia. Essa instituição sediou o VIII Congresso Iberoamericano de Ciência, Tecnologia e Gênero, em 2010. O Ibero tem por objetivo refletir sobre essa temática a partir das especificidades locais dos países de línguas espanhola $e$ portuguesa. A UFTPR teve uma proposta enviada em 2005 que foi desfavorável, o que talvez tenha sido um fator para o não envio de outras propostas nas chamadas posteriores.

A Universidade Federal da Bahia (UFBA) também conta com pesquisadoras com atuação no tema e enviou quatro projetos, dois deles aprovados - um da História, outro de Comunicação. Na UFBA, o Núcleo de Estudos Interdisciplinares sobre a Mulher (NEIM), atuante desde 1983, publicou Feminismo, Ciência e Tecnologia em 2002, em conjunto com a Rede Feminista Norte e Nordeste de Estudos e Pesquisas sobre Mulher e Relações de Gênero - REDOR. A UFBA conta com graduação e pós-graduação sobre Estudos Feministas e de Gênero e também tem se destacado por pesquisar educação, ciência e tecnologia com enfoque em gênero e ensino de ciências.

A Universidade de Santa Catarina (UFSC), que hospeda uma das principais publicações feministas, a Revista de Estudos Feministas (REF), contou com o envio de somente dois projetos, tendo um deles sido aprovado. A REF e os cadernos pagu concentram as publicações latino-americanas sobre gênero, ciências e tecnologias (Lopes et al., 2014). A UFSC conta com o Núcleo de Identidades de Gênero e Subjetividades (NIGS), desde 
1991. Uma das linhas de pesquisa do grupo é gênero e ciência, que realizou, em 2013, o Seminário Gênero e Ciência.

A Fundação Carlos Chagas (FCC), conhecida por pesquisas sobre gênero e trabalho, também tem pesquisadoras que publicam na área de Estudos em Gênero, Ciências e Tecnologias. Todas essas instituições - Unicamp, UFTPR, UFSC, UFBA e FCC - são conhecidas por sua atuação nos Estudos de Relações de Gênero, Mulheres e Feminismos e têm inserção, com maior e menor graus, nos Estudos de Gênero, Ciências e Tecnologias. Estas instituições poderiam ter tido uma participação maior na demanda de projetos nessa temática nas chamadas.

A Universidade Federal de Viçosa (UFV) foi a que conseguiu maior número de aprovações - quatro propostas enviadas, todas aprovadas. Aqui é importante ressaltar que três propostas foram enviadas pela mesma proponente, que foi aprovada nas três primeiras chamadas: 2005, 2008 e 2010.

A Universidade Federal de Minas Gerais (UFMG) contou com o envio de quatro propostas; três tiveram pareceres favoráveis, sendo duas delas, propostas enviadas pela mesma proponente da área de Educação, e a terceira aprovada da área de arqueologia. $\mathrm{O}$ fato de a mesma proponente enviar mais de uma proposta pode indicar que a primeira aprovação é um incentivo para a submissão de outras propostas no mesmo teor; o contrário também parece ser verdadeiro, a primeira desaprovação é um fator de inibição de outras submissões.

Já a participação do Centro Brasileiro de Pesquisas Físicas (CBPF) marca o pequeno número de iniciativas,como as das pesquisadoras da Física, que buscam promover a carreira de mulheres nas Ciências Exatas, em especial na Física. Essas pesquisadoras foram influenciadas pela discussão internacional sobre a participação das mulheres na pesquisa dentro da própria área de conhecimento. Elas têm tido destaque na busca por melhores condições na carreira científica para as mulheres e têm publicado trabalhos sobre a participação de mulheres na Física (Barbosa, Márcia; Lima, Betina S., 2013). 
Um olhar sobre o conteúdo dos projetos na área de Estudos sobre Gênero, Ciências e Tecnologias

Os projetos enviados na área de gênero, ciências $e$ tecnologias (74 propostas) foram enquadrados segundo o modelo já proposto por Margaret Lopes et al. (2014), que analisaram as publicações produzidas em nove Congresos Iberoamericanos de Ciencia, Tecnología y Género (Ibero) e em nove Jornadas Latinoamericanas de Estudos Sociais da Ciência e da Tecnologia (ESOCITE). Segundo as autoras, essas publicações foram analisadas com o objetivo de

identificar tendências, escolhas temáticas, dificuldades metodológicas e, em que medida, em alguns países latinoamericanos, os estudos de gênero conferem atenção aos estudos de CTS e estudos de CTS, atenção a gênero (Lopes, Maria Margaret et al., 2014).

Escolhemos essa classificação a despeito de outras anteriormente propostas (Citeli, Teresa, 2000; Minella, Luzinete S., 2013; Cabral, Carla, 2015) por considerá-la mais detalhada e adequada aos objetivos desta pesquisa. As categorias utilizadas são:

- Trajetórias/história de mulheres em Ciência e Tecnologia: nessa categoria foram enquadrados os artigos de abordagem histórica que tratavam tanto das consequências da sub-representação e da exclusão das mulheres da ciência e tecnologia quanto inclui os trabalhos dirigidos a "recuperar" a contribuição feminina no campo científico e tecnológico (Lopes, Maria Margaret, 2008; Sombrio, Mariana, 2016).

- Carreiras de mulheres em CT e Política Científica e Tecnológica: estão inseridas as publicações que tratam das desigualdades nas carreiras científicas (na ascensão e representação das mulheres por área do conhecimento), com análises sobre as dificuldades $e$ obstáculos enfrentados pelas cientistas. Em geral, esses estudos 
trazem abordagens mais sociológicas. Incluem-se aqui os estudos com base em dados cientométricos, e também os trabalhos, como este artigo, de análise de ações e políticas de combate à desigualdade de gênero no campo científico (Lima, Betina S., 2013; Tabak, Fanny, 2002; Lombardi, Rosa Maria, 2006; Osada, Neide. M.; Costa, Maria C. da, 2006; Velho, Léa; Leon, Helena, 1998; Rodrigues, Jeorgina G.; Guimarães, Maria Cristina S., 2016).

- Epistemologia/Teorias de gênero e C\&T: nessa linha estão enquadradas as pesquisas sobre o impacto de gênero na produção científica e tecnológica. As pesquisas tratam também dos princípios estruturantes do conhecimento científico tais como objetividade e neutralidade. São autoras americanas conhecidas nesta área, Evelyn Fox Keller, Sandra Harding e Donna Haraway. Aqui também consideramos que deveriam ser enquadrados os mapeamentos do campo de gênero e de campo de Estudos Sociais da Ciência (como fazemos, em parte, neste artigo) por entender que se trata de uma reflexão sobre produção científica sob o impacto de gênero (Cabral, Carla, 2006; 2015; Minella, Luzinete, 2013; Lopes, Maria Margaret et al. 2014).

- Construções científicas/tecnológicas de gênero em saúde, medicina e biotecnologia: nesse tópico, estão os estudos sobre as construções socioculturais nas áreas da saúde, estas pesquisas incluem as construções históricas de doenças/comportamentos segundo gênero, diferenças biológicas, estudos sobre corpo, tecnologias reprodutivas, menopausa, entre outros (Citeli, Maria Teresa, 2001; Feltrin, Rebeca; Velho, Léa, 2016; Rohden, Fabíola, 2001).

- Educação e GC\&T: são pesquisas que relacionam a educação e a produção de hierarquia de gênero tais como as variáveis que moldam as escolhas nas carreiras científicas; buscam explicar o gradual afastamento das meninas e jovens de disciplinas das Ciências Exatas. Esses trabalhos discutem o material apresentado nos livros didáticos, o formato dos currículos, entre outros (Casagrande, Lindamir; Carvalho, Marília G. C., 2014).

- Divulgação científica e mídia: imagens de gênero e C\&T: nesse eixo temático estão os trabalhos sobre a influência das imagens 
divulgadas no meio midiático que reproduzem estereótipos de gênero, contribuindo para a exclusão e invisibilidade das mulheres no campo científico e tecnológico (Pedreira, Anna Elisa, 2014).

- TICs e usos da C\&T: estão localizados os estudos sobre inclusão feminina nas tecnologias de comunicação que debatem questões sobre o uso dessas tecnologias (Rapkiewicz, C. E., 1998).

- Recursos naturais, desenvolvimento e saberes populares: estão inseridos os trabalhos que discutem os saberes tradicionais e que promovem a visibilização de novos sujeitos epistêmicos, como estudos sobre mulheres indígenas, negras, artesãs, parteiras, rurais, entre outros (Vasconcellos, Bruna; Velho, Léa, 2010).

$\mathrm{Na}$ tabela abaixo, apresentamos as propostas segundo a classificação de subtemas utilizada.

Tabela 9 - Classificação das propostas por subtema

\begin{tabular}{|l|c|c|c|}
\hline \multicolumn{1}{|c|}{ Subtemas em EGCT } & Desfavorável & Favorável & Total \\
\hline $\begin{array}{l}\text { Carreiras de mulheres em CT e } \\
\text { Política Científica e Tecnológica }\end{array}$ & 16 & 16 & 32 \\
\hline $\begin{array}{l}\text { Construções } \\
\text { científicas/tecnológicas de } \\
\text { gênero em saúde, medicina e } \\
\text { biotecnologia }\end{array}$ & 2 & 5 & 7 \\
\hline $\begin{array}{l}\text { Divulgação científica e mídia: } \\
\text { imagens de gênero e C\&T }\end{array}$ & 1 & 2 & 3 \\
\hline Educação e GC\&T & 6 & 1 & 7 \\
\hline $\begin{array}{l}\text { Epistemologia/teorias de gênero } \\
\text { e C\&T }\end{array}$ & 1 & 4 & 5 \\
\hline TICs e usos da C\&T & 1 & 4 & 5 \\
\hline $\begin{array}{l}\text { Trajetórias/história de mulheres } \\
\text { em C\&T }\end{array}$ & 12 & 3 & 15 \\
\hline Total Global & 39 & 35 & 74 \\
\hline
\end{tabular}

Cerca de $43 \%$ das propostas enviadas (32 propostas do total de 74) foram enquadradas em Carreiras de mulheres em CT $e$ 
cadernos pagu(48), 2016:e164805 Betina S. Lima e Maria Conceição da Costa

Política Científica Tecnológica. Essa concentração foi observada em outros trabalhos (Lopes, Maria M. et al., 2014; Minella, Luzinete S., 2013, Cabral, Carla G., 2015). Alguns fatores poderiam explicar tal configuração:

\begin{abstract}
A prevalência da primeira tendência talvez se explique em razão de vários fatores, por exemplo, o alto potencial explicativo dos temas abordados nesses estudos; a atração exercida pelo visível incremento do acesso $e$ da permanência das mulheres no campo científico, inclusive em áreas antes prioritariamente masculinas; $e$, ainda, as relativas facilidades de acesso às informações sobre os contextos atuais. É provável que tal prevalência se explique também em virtude da influência da formação empírica das pesquisadoras, bem como de outros fatores a serem pesquisados (Minella, Luzinete S., 2013:125).
\end{abstract}

Também podemos afirmar que a motivação das discussões sobre gênero e ciências foi a sub-representação das mulheres (Rossiter, Margaret, 1982); esse também pode ser um fator explicativo para a predominância de estudos na linha de pesquisa sobre carreiras. Outra justificativa é que essa vertente congrega os poucos trabalhos em que pesquisadoras de áreas historicamente masculinas, como a Física, se propõem a analisar as condições específicas das mulheres nas ciências e tecnologias (Barbosa, Marcia C. B.; Lima, Betina S., 2013).

Esses estudos sobre Carreiras de mulheres em CT e Política Científica e Tecnológica são os que dialogam mais diretamente com os objetivos do Programa Mulher e Ciência, uma vez que os resultados dessas pesquisas poderiam subsidiar a superação dos desafios do programa. Nessa vertente, encontramos estudos sobre a divisão sexual do trabalho (em especial sobre uso de tempo $e$ maternidade) e carreira científica, sobre inserção de meninas nas carreiras científicas e tecnológicas, sobre ascensão e produtividade das pesquisadoras, sobre trajetórias e obstáculos em diferentes áreas (física, engenharias, biologia, economia doméstica, medicina veterinária, pedagogia, computação, ciências humanas), sobre 
divisão de trabalho na universidade, sobre a participação feminina na gestão da ciência e tecnologia, participação das mulheres em programas como Programa de Pesquisas Antártico Brasileiro e Institutos Nacionais de Ciência e Tecnologia e participação das pesquisadoras negras na produção do conhecimento, dentre outros.

A segunda linha de pesquisa mais representativa em termos numéricos é sobre história das mulheres nas ciências. Esta vertente tem o importante papel de visibilizar as trajetórias e contribuições das muitas mulheres que fizeram parte da história da ciência. Cabe destacar que a "invisibilidade" das mulheres cientistas também é uma construção historiográfica. No Brasil, esta vertente se defronta com a própria desvalorização da área de História e nos Estudos Feministas e de Gênero:

Cabe discutir o papel que os próprios estudos de gênero e a historiografia feminista locais têm jogado na construção da invisibilidade da área de estudos de gênero e ciências, em um quadro senão de negação, de ausência de qualquer valorização da História das Ciências como um todo no Brasil e em diversos países latino-americanos (Lopes, M. Margaret; Costa, Maria C. da, 2005:82).

Nessa abordagem histórica, há propostas de pesquisa sobre as pioneiras nas ciências (por exemplo, a trajetória de Marta Vannucci), sobre as contribuições das mulheres pesquisadoras na Física, na Psicologia, na Geografia, na Biomedicina, na Administração, e a contribuição das mulheres em determinadas unidades de ensino e pesquisa tais como a Embrapa.

Outro ponto é que não se trata apenas de "resgatar" a história das mulheres cientistas, mas de questionar, segundo as perspectivas de gênero, a própria construção histórica, frequentemente, totalizante e produzida segundo os papéis de gênero. Outro desafio dessa linha de pesquisa é não "reproduzir" a história das "vencedoras", tornando-as "super mulheres", e sim, buscar suas trajetórias científicas, de tropeços e acertos, a partir de 
contextos sociais, culturais e institucionais da própria ciência. A escrita de "histórias" de cientistas como seres excepcionais produz modelos inalcançáveis e, portanto, reforça que a ciência não é uma atividade para "qualquer" mulher.

O subtema Educação e GC\&T surge em terceiro lugar juntamente com a linha Construções científicas/tecnológicas de gênero em saúde, medicina e biotecnologia, que vem se destacando na área de EGCT. A linha de pesquisa sobre Educação e GC\&T é responsável pelo segundo lugar com maior número de trabalhos nos congressos da área de ECGT (Lopes, M. Margaret et al., 2014). Aqui estão os estudos sobre ensino de ciências e sobre formação docente nessa atividade.

Já na linha de Construções científicas/tecnológicas de gênero em saúde, medicina e biotecnologia, há projetos sobre técnicas de reprodução assistida, sobre menopausa, reprodução e genética.

A linha TICs e usos da C\&T recebeu cinco propostas sobre cultura digital, inclusão digital, adoção de software livre a partir da perspectiva de gênero, representações sociais na informática.

A vertente Divulgação científica e mídia: imagens de gênero e C\&T, com somente três projetos enviados, é a que menos recebeu propostas. Encontramos duas propostas da mesma proponente, com o mesmo objeto, que trata das representações das cientistas pela mídia brasileira e no imaginário dos adolescentes, e uma sobre divulgação científica e a participação das mulheres.

No âmbito dos Estudos sobre Gênero, Ciências e Tecnologias, observa-se a marginalidade das propostas que têm como foco o estudo da tecnologia e suas interfaces. Os dados encontrados nas chamadas são confirmados por outros estudos locais (Lopes, M. Margaret et al., 2014). Foram encontradas nove propostas, cerca de $12 \%$, que referem-se à tecnologia no título da proposta, conforme dados apresentados no quadro abaixo: 
Tabela 10 - Número de projetos com interface com as tecnologias por linha de pesquisa nos EGCT e por parecer

\begin{tabular}{|l|c|c|c|}
\hline \multicolumn{1}{|c|}{ Linhas de Pesquisa } & DF & FV & Total \\
\hline $\begin{array}{l}\text { Carreiras de mulheres em CT } \\
\text { e Política Científica e } \\
\text { Tecnológica }\end{array}$ & 3 & 1 & 4 \\
\hline TICs e usos da C\&T & 1 & 4 & 5 \\
\hline Total & 4 & 5 & 9 \\
\hline
\end{tabular}

As propostas com interface com a tecnologia estão concentradas em duas linhas de pesquisa, segundo o material analisado: na temática de "TICs e usos da C\&T" e "Carreiras de mulheres em CT e Política Científica e Tecnológica". No caso desta última temática, trata-se de propostas sobre inserção $e$ atuação das mulheres em áreas mais tecnológicas como engenharias. Os projetos que abordam o uso da tecnologia estão concentradas na linha "TICs e usos da C\&T". Essa também foi uma constatação na análise de trabalhos apresentados nos Congresos Iberoamericanos de Ciencia, Tecnología y Género (Ibero) e nove Jornadas Latino-americanas de Estudos Sociais da Ciência e da Tecnologia (ESOCITE):

A incorporação das discussões sobre tecnociência, suas apropriações e crítica social, sobretudo em suas dimensões de gênero é pouco visível nos trabalhos consultados. Os poucos trabalhos encontrados na área, referem-se às intersecções entre gênero e TICs (Lopes, M. Margaret et al., 2014:11).

\section{Passos lentos para a interseccionalidade e a transversalidade}

A fim de encontrar indícios sobre a pesquisa interseccional nos Estudos de Gênero, Ciências e Tecnologias, buscamos nos títulos das propostas palavras relacionadas a classe, raça, etnia e geração. As propostas foram classificadas em três categorias 
interseccionais: 1) geração, 2) classe e 3) etnicidade e raça. Obviamente, pode haver projetos que não tenham no título as palavras de interseccionalidade que buscamos e, ainda assim, possuírem uma proposta interseccional. $O$ inverso também é verdadeiro. As propostas podem ter indícios de interseccionalidade, $e$, na prática, não terem se desenvolvido dessa forma, ainda mais se considerarmos os desafios colocados pela interseccionalidade na prática da pesquisa (McCall, Leslie, 2005). No entanto, entendemos a busca por palavras-chave relacionadas à interseccionalidade nos títulos como um indicador para dimensionar a frequência da análise interseccional na pesquisa dessa área.

Ao separar os projetos enquadrados na área gênero, ciências e tecnologias, encontramos um percentual semelhante ao quadro geral das propostas do campo de gênero e feminista enviadas para as quatro chamadas (total: 1371). No total de projetos enquadrados como gênero, ciências e tecnologias (74), somente cerca de $10 \%$ apresentam nos títulos menção a uma proposta interseccional. Esse percentual é relativamente baixo se considerarmos a centralidade e a importância da perspectiva interseccional nas pesquisas feministas e de gênero. Podemos afirmar que a perspectiva interseccional confere complexidade às pesquisas $e$ incorpora as críticas referentes à não essencialização $e$ homogeneização do constructo mulher. Esse número ainda diminui, se considerarmos que do total de quatro propostas sobre geração, duas são da mesma pesquisadora em chamadas distintas; e do total de três propostas em etnicidade e raça, duas são do mesmo pesquisador.

Tabela 11 - Classificação das propostas por intersecção

\begin{tabular}{|l|c|c|c|}
\hline \multicolumn{1}{|c|}{ Intersecções } & Desfavorável & Favorável & Total \\
\hline etnicidade e raça & 2 & 1 & 3 \\
\hline geração & 1 & 3 & 4 \\
\hline total & 3 & 4 & 7 \\
\hline
\end{tabular}


A perspectiva geracional tem sido um pouco mais frequente do que a de raça e etnicidade na nossa pesquisa. Sem dúvida, faltam estudos sobre raça e etnicidade nas pesquisas de gênero, ciências e tecnologias, conforme aponta Minella (2013). A inserção de raça/cor no Currículo Lattes permitiu dimensionar a participação das mulheres negras nas bolsas do Conselho Nacional de Desenvolvimento Científico e Tecnológico (CNPq). A disponibilidade desse dado poderá fomentar estudos e pesquisas com recorte étnico-racial. Destaca-se, por exemplo, que a participação das mulheres autoclassificadas como pretas é muito menor do que das mulheres brancas (Tavares, Isabel, et al., 2015).

As lacunas interseccionais também podem ser percebidas nas ações do Programa Mulher e Ciência. Não há uma ação direcionada, por exemplo, para mulheres negras. Sem dúvida, medidas como a prorrogação da bolsa em caso de parto ou adoção beneficiam todas as que aderem à maternidade. No entanto, são necessárias algumas ações específicas para maior participação das mulheres negras e indígenas.

Segundo os dados coletados, outra lacuna é a pouca frequência sobre estudos com a perspectiva de classe. É importante dizer que hoje os dados sobre classe são mais difíceis de obter do que os de raça/etnia já dispostos no Lattes. No entanto, a condição de classe também é um fator de acesso à educação e à formação científica. As ações afirmativas com esse recorte surgem dessa constatação.

A incorporação das distintas perspectivas interseccionais é tão necessária quanto desafiadora, seja para a pesquisa seja para a formulação da política científica.

\section{Outras ações: meninas e jovens fazendo Ciências Exatas, Engenharias $e$ Computação}

Em 2013, foi implementada, no âmbito do Programa Mulher e Ciência, uma ação diretamente voltada para o fomento da participação das mulheres nas ciências e tecnologias. Trata-se da chamada pública "Meninas e Jovens Fazendo Ciências Exatas, 
Engenharias e Computação" com o objetivo de selecionar propostas para apoio financeiro a projetos que visem estimular a formação de mulheres para as carreiras de Ciências Exatas, Engenharias e Computação no Brasil, combatendo a evasão que ocorre principalmente nos primeiros anos desses cursos $e$ despertando o interesse vocacional de estudantes do sexo feminino do ensino médio e da graduação por essas profissões $e$ para a pesquisa cientifica e tecnológica. ${ }^{10}$

Essa ação foi concebida para fomentar a participação feminina em áreas em que as mulheres estão sub-representadas desde o início da carreira. Assim, visa combater a segregação territorial ou horizontal que ocorre no sistema de ciência $e$ tecnologia por meio da divisão sexual das áreas do conhecimento.

A chamada contou com um significativo aporte de recursos de $\mathrm{R} \$ 11$ milhões, resultado da parceria do CNPq com MCTI, SPM e Petrobrás. Os projetos deveriam ser coordenados por um/a professor/a universitário/a das áreas previstas e deveriam incluir estudantes do ensino médio e da graduação das áreas de Exatas, Engenharias e Computação e um/a professor da escola coexecutora de ensino médio. Foram oferecidas bolsas para as meninas e jovens e para a/o professor/a do ensino médio que tenha vínculo empregatício/funcional com a instituição coexecutora do projeto.

Esse formato de projeto envolve a formação de uma equipe em torno do desenvolvimento de uma pesquisa científica ou de atividades de divulgação científica. Busca-se despertar o interesse pela atividade científica e tecnológica - em especial das áreas selecionadas na chamada - em meninas do ensino médio $e$ combater a evasão de jovens da graduação em áreas em que as mulheres ainda são minoria.

A chamada recebeu 528 projetos e foram aprovados 325 deles. Foram contempladas propostas em diversas áreas do conhecimento. Dentre as listadas na chamada, as áreas com o maior número de propostas foram a Engenharia Química,

${ }^{10}$ Trecho da Chamada 18/2013. 
Química, Ciência da Computação, Engenharia da Computação, Engenharia Mecânica, Engenharia Elétrica e Física. Nas três modalidades de bolsas previstas, foram contempladas aproximadamente 1.500 bolsistas em todo país.

Foram enviados projetos vinculados a 165 instituições e foram aprovados projetos de 107 instituições. A região com o maior número de projetos aprovados foi o Nordeste (94 projetos $29 \%$ ), seguido do Sudeste (83 projetos - 26\%) e do Sul (82 projetos $-25 \%$ ). A região Nordeste tem tido uma participação destacada nas ações do Programa Mulher e Ciência, na aprovação de propostas nas chamadas de relações de gênero, mulheres $e$ feminismos.

Um resultado do lançamento dessa chamada é o efeito multiplicador da iniciativa pioneira de fomentar mulheres em áreas consideradas masculinas. Em 2015, a Fundação Carlos Chagas, em parceria com o Fundo ELAS e o Instituto Unibanco, lançou o projeto "Elas nas Exatas" que "tem o objetivo de contribuir para a redução do impacto das desigualdades de gênero nas escolhas profissionais e no acesso à educação superior das estudantes". ${ }^{11}$ Ao implementar essa iniciativa, o $\mathrm{CNPq}$ e demais parceiros sinalizam a importância de fomentar a participação feminina nas ciências e incentivam a realização de outras iniciativas.

Sobre os resultados dos projetos desenvolvidos, foi possível constatar, a partir das apresentações de alguns projetos desenvolvidos na II Conferência de Mulheres na Física e na matéria divulgada na página do $\mathrm{CNPq}^{12}$, que a participação nos projetos influenciou a escolha das meninas do ensino médio para a continuidade de sua formação educacional. $\mathrm{O}$ ingresso na universidade tornou-se um objetivo mais próximo e as escolhas de curso foram orientadas pela vivência no projeto. A maioria das meninas ouvidas afirmou que optaria por áreas afins à chamada.

\footnotetext{
${ }^{11}$ [http://www.fundosocialelas.org/elasnasexatas/ - acesso em: 14 mar. 16].

12 [http://cnpq.br/web/guest/noticiasviews/-

/journal_content/56_INSTANCE_a6MO/10157/4167190 - acesso em: 14 mar. 2016].
} 
No caso das jovens da graduação, elas se sentiram mais motivadas a permanecer no curso. Esses resultados são semelhantes aos que estão sendo reportados por atores envolvidos (bolsistas, orientadores, coordenadores) na Iniciação Científica tanto na graduação quanto no ensino médio. A experiência de envolvimento com a pesquisa orientada por um/a pesquisador/a qualificado/a tem direcionado escolhas no ensino médio e tem gerado, no ensino superior, maior envolvimento com as atividades do curso bem como aprofundado os conhecimentos apresentados na graduação (Massi, Luciana; Queiroz, Salete, 2010).

Outro impacto relatado ocorreu na própria escola. As bolsistas tiveram mais visibilidade na escola e outros/as alunas se interessaram pelo projeto. A/o professor/a tutor/a de ensino médio, em alguns casos, demonstrou interesse em dar continuidade à sua formação e ingressar na pós-graduação. Os projetos dessa chamada estão finalizando e cabe, após sua finalização, uma análise mais apurada e sistemática dos resultados alcançados.

Pode-se considerar que o lançamento da chamada Meninas e jovens fazendo nas Ciências Exatas, Engenharias e Computação poderia induzir a discussão de gênero e a incorporação da perspectiva sexo/gênero em outras áreas de pesquisa. Ou seja, a própria existência de uma chamada específica para o sexo feminino possibilitaria questionamentos sobre a necessidade dessa medida e pressuporia uma formulação de proposta com esse objetivo específico. No entanto, em ata, o comitê de julgamento dessa chamada observou:

Para algumas propostas se observou que embora o projeto científico estivesse bem embasado, não havia uma reflexão sobre temática do gênero. Muitas vezes, não foi observado nem mesmo uma descrição da abordagem proposta para inserção das meninas no grupo de pesquisa, a fim de efetivamente motivar as alunas a seguirem carreiras nesta área. O comitê decidiu priorizar propostas que, além de terem mérito científico/técnico, explicitamente abordaram as questões comentadas acima, com o intuito de sinalizar 
para a comunidade acadêmica o que se espera de projetos nesta linha de chamadas (CNPq, 2013).

A partir dessa constatação, o comitê de julgamento da chamada recomendou que as propostas incorporassem

as questões de gênero nas quais o projeto irá se focar, apresentar claramente as estratégias a serem usadas para contribuir para esta questão e sugerir formas de acompanhamento e avaliação do impacto das ações propostas (CNPq, 2013).

Por meio dessas informações, percebe-se como a transversalização da perspectiva de gênero não é trivial.

Temos o duplo desafio de fomentar os estudos sobre ciência e tecnologia nos estudos de gênero quanto de ampliar a incorporação da perspectiva de gênero em áreas nas quais não há acúmulo dessa discussão. Se há uma notória dificuldade em caracterizar projetos de inclusão de meninas e jovens em uma chamada caracterizada para esse fim, consideramos que o ideal de incorporar gênero na própria pesquisa, em qualquer área do conhecimento, apresenta-se ainda uma tarefa mais árdua.

Essa incorporação promoveria uma mudança na cultura das ciências, tornando o conhecimento mais livre dos preconceitos de gênero e do androcentrismo, e provavelmente fomentaria maior inserção feminina em todas as áreas do conhecimento. Esse, sem dúvida, é o maior desafio da área, pois exige que a capacitação feminista e de gênero ocorra em todas as disciplinas e não somente nas de Humanas e Sociais.

O Programa Mulher e Ciência é um marco nas políticas de equidade de gênero na ciência e tem avançado em muitos aspectos: na visibilidade das questões de gênero na participação da ciência e tecnologia, na consolidação dos Estudos Feministas e de Gênero, na implementação de medidas para fomentar a participação feminina, dentre outros. No entanto, à medida que avançamos, percebemos o quanto ainda é necessário percorrer. 
A consolidação dos Estudos de Gênero, Ciências e Tecnologias também faz parte do caminho que ainda precisamos percorrer. Nesse sentido, é preciso avançar na implementação de mecanismos de fomento a essa área, em suas múltiplas vertentes de pesquisa. A ampliação na produção desses conhecimentos pode contribuir para o avanço da equidade de gênero na C\&T.

Como ocorre nos Estudos Feministas e de Gênero como um todo, é necessária maior incorporação da interseccionalidade, em especial, para o estudo de Carreiras de mulheres em CT e Política Científica e Tecnológica, uma vez que a participação feminina é perpassada por marcadores importantes como raça/cor, classe, geração, localidade.

O Programa Mulher e Ciência desbravou os caminhos para a equidade de gênero nas ciências e tecnologias. Essa trajetória percorrida nos permite perceber o quanto já avançamos e quais são os próximos desafios para o avanço da equidade de gênero na C\&T.

\section{Referências bibliográficas}

BARBOSA, Márcia C. B.; LiMA, Betina S. Mulheres na Física no Brasil: por que tão poucas? E por que tão devagar? In: YANNOULAS, Silvia Cristina (org.). Trabalhadoras - Análise da Feminização das Profissóes e Ocupaçôes. Brasília, Editorial Abraré, 2013, pp.01-304.

CABral, Carla G. Pelas telas, pela janela: o conhecimento dialogicamente situado. cadernos pagu (27), Campinas, Núcleo de Estudos de Gênero-Pagu/Unicamp, 2006, pp.63-97.

- Os estudos feministas da ciência e da tecnologia no Brasil: Reflexões sobre estilos e coletivos de pensamento. Revista Ártemis, vol. XX. João Pessoa (PB), ago-dez 2015, pp.76-91.

CASAgrande, Lindamir S.; CARVAlHO, Marilia Gomes de. Relações de gênero nas aulas de matemática: perceptíveis ou ocultas? Cadernos de Gênero e Tecnologia (CEFET/PR), vol. 31-32, 2014, pp.37-50.

Citeli, Maria T. Mulheres nas ciências: mapeando campos de estudo. cadernos pagu (15), Campinas, Núcleo de Estudos de Gênero Pagu/Unicamp, 2000, pp.39-75. 
- Fazendo diferenças: teorias sobre gênero, corpo $e$ comportamento. Revista Estudos Feministas, vol. 9, $\mathrm{n}^{\circ} 1$, Florianópolis, 2001, pp.131-145.

CNPq. Relatório da Reunião de Avaliação do Edital Chamada 18/2013 MCTI/CNPq/SPM-PR/Petrobrás Meninas e Jovens Fazendo Ciências Exatas, Engenharias e Computação, Brasília, 2013.

DinIZ, Débora; FolTRAN, Paula. Gênero e feminismo no Brasil: uma análise da Revista Estudos Feministas. Revista Estudos Feministas, vol. 12, nº especial, Florianópolis, 2004, pp.245-253.

FeltRIN, Rebeca B.; VelHO, Lea. Representaciones del cuerpo femenino en la menopausia: estudio etnográfico en un hospital-escuela brasileño. Sexualidad, Salud y Sociedad, vol. 1, Rio de Janeiro, 2016, pp.148-174.

Garcia, Marta I. G.; SedeÑo, Eulália P. Ciência, gênero, tecnologia. In: Dos SANTOS, Lucy W; ICHIKAWA, Elisa Y.; CARGANO, Doralice de F. (Org). Ciência, tecnologia e gênero - desvelando o feminino na construção do conhecimento.. Londrina, IAPAR, 2006, pp.33-72.

HARAWAY, Donna. Saberes localizados: a questão da ciência para o feminismo e o privilégio da perspectiva parcial. cadernos pagu (5), Campinas (SP), Núcleo de Estudos de Gênero - Pagu/Unicamp, 1995, pp.7-42.

HARDING, Sandra. Ciencia y feminismo. Barcelona, Morata, 1996.

KELLER, Evelyn F. Reflexiones sobre Género y Ciencia. Valencia, Edicions Alfons el Magnànim, 1989.

. Qual foi o impacto do feminismo na ciência? cadernos pagu (27), Campinas (SP), Núcleo de Estudos de Gênero-Pagu/Unicamp, 2006, pp.13-34.

LIMA, Betina Stefanello. O labirinto de cristal: as trajetórias das cientistas na Física. Revista de Estudos Feministas (21), n³, Florianópolis (SC), 2013, pp.883-903.

LOMBARDI, Rosa Maria. Engenheira \& gerente: desafios enfrentados por mulheres em posições de comando na área tecnológica. Revista Tecnologia e Sociedade, vol. 3, 2006, pp.63-86. 
cadernos pagu(48), 2016:e164805 Betina S. Lima e Maria Conceição da Costa

LOPES, Maria M. A ciência não é uma jovem de costumes fáceis: aspectos das relações de Gênero na História das Ciências no Brasil. Cadernos do IG/UNICAMP, vol. 2, n¹, Campinas (SP), 1992, pp.90-107.

. "Aventureiras" nas ciências: refletindo sobre Gênero e História das Ciências Naturais no Brasil. cadernos pagu (10), Campinas (SP), Núcleo de Estudos de Gênero - Pagu/Unicamp, 1998, pp.345-368.

- Sobre convenções em torno de argumentos de autoridade. cadernos pagu (27), Campinas (SP), Núcleo de Estudos de Gênero Pagu/Unicamp, dez. 2006, pp.35-61.

. Proeminência na mídia, reputação em ciências: a construção de uma feminista paradigmática e cientista normal no Museu Nacional do Rio de Janeiro. História, Ciências, Saúde-Manguinhos (15), Rio de Janeiro, 2008, pp.73-95.

LOPES, Maria M.; COSTA, Maria C. Problematizando ausências: mulheres, gênero e indicadores na história das ciências. In: MORAES, Maria L. Q. (org.) Gênero nas fronteiras do Sul. Campinas (SP), Núcleo de Estudos de Gênero - Pagu/Unicamp, 2005, pp.75-83.

LOPES, Maria M. et alii. Intersecções e interações: gênero em ciências e tecnologias na América Latina. In: KREIMER, P. et alii (org.). Perspectivas latinoamericanas en el estudio social de la ciencia, la tecnología y el conocimiento. Cidade do México, Siglo XXI, 2014, pp.233-243.

MCCALL, Leslie. The Complexity of Intersectionality. Signs: Journal of Women in Culture and Society, vol. 30, n³, Chicago, 2005, pp.7711800 .

Martin, Emily. A Mulher no Corpo: Uma Análise Cultural da Reprodução. Rio de Janeiro, Garamond, 2006.

MASSI, Luciana; QUEIROZ, Salete L. Estudos Sobre a Iniciação Científica no Brasil: uma revisão. Cadernos de Pesquisa, vol. 40, n 139 , São Paulo, jan./abr. 2010, pp.173-197.

MinELlA, Luzinete S. Temáticas prioritárias no campo de gênero e ciências no Brasil: raça/etnia, uma lacuna? cadernos pagu (40), Campinas (SP), Núcleo de Estudos de Gênero-Pagu/Unicamp, junho 2013, pp.95-140. 
MiQueO, Consuelo et alii. Ellas também cuentam Científicas en los comités de revistas biomédicas. Zaragoza, Prensas Universitarias Universidad Zaragoza, 2011.

OSADA, N. M.; CostA, M. C. A construção social de gênero na Biologia: preconceitos e obstáculos na biologia molecular. cadernos pagu, (27), Campinas (SP), Núcleo de Estudos de Gênero-Pagu/Unicamp, 2006, pp.279-299.

PedreIRA, Anna Elisa F. Gênero, Ciência e TV: Representações dos Cientistas no Jornal Nacional e no Fantástico. Dissertação (Mestrado em Ensino em Biociências e Saúde), Fundação Oswaldo Cruz, Instituto Oswaldo Cruz, Rio de janeiro, 2014.

Piscitelli, Adriana; Beleli, Iara; LOPES, Maria Margaret. Cadernos Pagu: contribuindo para a consolidação de um campo de estudos. Revista Estudos Feministas, Florianópolis, vol. 11, n 1, junho 2003, pp.242-246.

RAPKIEWICZ, C. E. Informática: domínio masculino? cadernos pagu (10), Campinas (SP), Núcleo de Estudos de Gênero-Pagu/Unicamp, 1998, pp.169-200.

RodrigueS, Jeorgina Gentil; GuimARAES, Maria Cristina Soares. A Fundação Oswaldo Cruz e a ciência no feminino: a participação feminina na prática e na gestão da pesquisa em uma instituição de ensino e pesquisa. cadernos pagu (46), Campinas (SP), Núcleo de Estudos de Gênero-Pagu/Unicamp, 2016, pp.197-222.

ROHDEN, Fabíola. Uma ciência da diferença: sexo e gênero na medicina da mulher. Rio de Janeiro, Fiocruz, 2001.

ROssiter, Margaret. Women scientists in America: Struggles and strategies to 1940. Baltimore, The Johns Hopkins University Press, 1982.

. The Matthew Matilda effect in Science. Social Studies of Science, vol. 23, n² 2, maio 1993, pp.325-341.

SCAVONE, Lucila. Perfil da REF dos anos 1999-2012. Revista Estudos Feministas, vol. 21, n 2, Florianópolis, agosto 2013, pp.587-596.

SCHIEBINGER, Londa. O Feminismo mudou a ciência? São Paulo, EDUSC, 2001. 
cadernos pagu(48), 2016:e164805 Betina S. Lima e Maria Conceição da Costa

. Mais mulheres na ciência: questões de conhecimento. História, Ciências, Saúde - Manguinhos, vol.15, supl., Rio de Janeiro, junho 2008, pp.269-281.

SomBriO, Mariana M. O. Gender, Museums and Science: Wanda Hanke's Ethnological Collections (1933 - 1958). HOST - Journal of History of Science and Technology, vol. 10, 2016, pp.33-69.

TABAK, Fanny. O Laboratório de Pandora: estudos sobre a ciência no feminino. Rio de Janeiro, Garamond, 2002.

TAVARES, Isabel; BRAGA, M. Lúcia; LiMA, Betina. Análise sobre a participação de negras e negros no sistema científico [http://cnpq.br/web/guest/noticias-popularizacao/journal content/56 INSTANCE a6MO/10157/2526062 - acesso em: 30 set 2015].

VASCONCELlOS, Bruna. M.; VELHO, Lea. Relações de gênero e tecnologia nas cozinhas da Associação de Mulheres Agroecológica. In: VII Congresso Iberoamericano de Ciência, Tecnologia e Gênero, 2010, Curitiba.

VELHO, Léa; LEON, Helena. A construção social da produção científica por mulheres. cadernos pagu (10), Campinas-SP, Núcleo de Estudos de Gênero - Pagu/Unicamp, 1998, pp.309-344. 